\title{
Investigation of Short Permanent Magnet and Stator Flux Bridges Effects on Cogging Torque Mitigation in FSPM Machines
}

\author{
Chun Gan, Member, IEEE, Jianhua Wu, Mengjie Shen, Qingguo Sun, \\ Yihua Hu, Senior Member, IEEE, and Wenping Cao, Senior Member, IEEE
}

\begin{abstract}
Flux-switching permanent magnet (FSPM) machines are gaining in popularity due to their robustness, wide speed range, high torque, and high power density. However, their strong cogging torque can lead to vibration and noise due to the doublesaliency structure. This paper investigates the effects of the short permanent magnet $(P M)$ and stator flux bridge (FB) on the cogging torque reduction of three-phase 12/10-pole FSPM machines. Four different FSPM machines, including an innerinner topology, an inner-outer topology, an outer-inner topology, and an outer-outer topology, are developed and analyzed with both short PM and stator FB. The configurations are obtained by placing the $\mathrm{FB}$ at inner/outer stator lamination and reducing the PM towards inner/outer directions. The cogging torque, average output torque, and PM utilization ratio of different topologies are extensively studied and compared by the finite element method (FEM). Finally, prototype machines are manufactured and tested. The experimental results have validated the numerical models and the effectiveness of the developed machine in reducing the cogging torque. The results also suggest that the outer-inner topology is more effective to reduce the cogging torque, which not only reduces the utilization of the PM materials, but also mitigates the cogging torque at only slight cost of torque performance.
\end{abstract}

Index Terms - Short permanent magnet (PM), stator flux bridge (FB), flux-switching permanent magnetic (FSPM) machine, cogging torque, finite element method (FEM).

\section{INTRODUCTION}

In recent years, flux-switching permanent magnet (FSPM) machines have attracted much attention for research and industrial applications, due to their characteristics of robustness, wide speed range, high torque, and high power density [1]-[8], making them especially suited for high-performance and highspeed automotive applications. The FSPM machine is a novel brushless machine, where the permanent magnets and concentrated windings are both installed in the stator next to each other so as to produce flux-switching high-torque capabilities. This is different to conventional permanent magnet synchronous motors (PMSMs). However, the FSPM machine exhibits a higher their cogging torque is higher than traditional permanent-magnet machines PMSMs, due to their doublesaliency structure and high air-gap flux density. The cogging torque leads to undesirable vibration and noise, particularly in low-speed operations [9]-[11], and thus is not desirable for high-performance vehicles.

In order to reduce the cogging torque of the FSPM machines, some advanced technologies have been developed accordingly reported in the literature, which fall into two categories: 1)
Modification of machine design to minimize the cogging torque. 2) Development of new control strategies to combat the cogging torque.

Since permanent magnets (PMs) are installed in the stator, the rotor construction can be made simple and robust, due to no PMs and windings. Thus, some schemes are presented to reduce the cogging torque by improving the rotors. In [18], the cogging torque mechanism in FSPM machines is investigated by analyzing the flux density distribution, and a simple teeth notching technique is proposed for cogging torque reduction at the cost of slightly reducing the average output torque. The influence of the slot width, slot depth, and slot shape angle on the cogging torque is analyzed in [19] for rotor tooth notching scheme. In [15], a rotor teeth pairing method is proposed for the cogging torque reduction, where the rotor has two different tooth widths alternately. A new rotor teeth axial pairing technique is proposed in [16] to reduce the cogging torque, by using two types of rotor tooth widths connected in axial, which is more feasible and effective than the technique with rotor teeth pairing. The effects of the rotor pole arc width on the cogging torque, torque ripple of FSPM machines are investigated in [17], and three techniques based on the optimization of rotor pole configurations are put forward and compared, including a uniform structure, a rotor step skewed structure, and a rotor axial pairing structure. An FSPM machine with a twisted rotor is presented in [20], which exhibits a higher torque density and lower cogging torque than conventional machines. A new pole shaping method is proposed in [21] to reduce the cogging torque for FSPM machines, by introducing flange in the rotor teeth. In [22], a novel dual rotor structure is designed, which suppresses the cogging torque and torque ripple. For the stator developments, a novel 6/4-pole dual-stator structure is proposed to resolve the high cogging torque in conventional single-stator forms [23]. Adding stator magnetic bridge in adjacent stator tooth is presented in [24], which not only alleviates the cogging torque, but also reduces the manufacturing complexity and achieves a more robust stator configuration, while the effects of different placing positions for the FB are not investigated in details. The FSPM machine with $5 \mathrm{~mm}$ PM left and right air gaps is presented in [25], and three PM locations including PM-top, PM-bottom, and PMmiddle are compared by using two PM materials in [26]. However, the detailed comparison of different PM lengths and stator FB placing positions on cogging torque mitigations have not been presented and investigated yet. To increase the 
reliability of FSPM machines, multiphase topologies are also developed [27], [28], offering a reduced cogging torque.

In addition to modifying the machine design, several methods are focused on the control strategies to reduce the cogging torque for FSPM machines. In [12], current harmonics are injected into the current reference to compensate the fundamental and second order harmonic components of the cogging torque. A new method of cogging torque compensation for an external-rotor 12/22 FSPM machine is proposed in [13], by employing the iterative learning control (ILC) and direct torque control, without dynamic performance degradation. In [14], a model predictive flux control strategy with ILC is presented to mitigate the cogging torque and torque ripple for three-phase FSPM machines. However, the cogging torque control schemes are not suited for various operational conditions and different control strategies, where the cogging torque cannot be completely mitigated. Considering this point, some other technologies are presented to improve the machine topology, including rotor improvements [15]-[22], stator developments [23]-[26], and multiphase machine design [27], [28].

This paper proposes the use of stator flux bridges (FB) to mitigate the cogging torque in three-phase 12/10-pole FSPM machines. The machines with different FB positions and thickness are firstly analyzed and compared. Then, four FSPM machine topologies with both short PM and stator FB are developed, including the inner-inner topology, inner-outer topology, outer-inner topology, and outer-outer topology. The cogging torque, average output torque, PM utilization, and torque ripple under different $\mathrm{PM}$ length and stator FB positions are investigated by a two-dimensional (2D) finite element method (FEM) in Ansoft environment. Two selected machine topologies are manufactured for experimental validation and comparison, including the stator FB based outer-inner FSPM machine with short PM length and stator FB based outer-inner topology with regular PM length. The simulation and experimental results are presented to confirm the effects of reducing the PM length and placing the FB in FSPM machines. The developed topology not only reduces the utilization of the PM materials, but also mitigates the cogging torque at only slight cost of machine performance.

This paper is organized as follows. Section II presents the FSPM machine with stator FB and analyzes the cogging torque under different FB thickness and positions. In Section III, the cogging torque of developed machines is analyzed and compared in details by FEM. Experimental results are carried out in Section IV to verify the effectiveness of the developed machine. Finally, conclusions are given in Section V.

\section{FSPM Machines with STATOR FB}

\section{A. Cogging Torque in FSPM Machines}

Fig. 1 shows the configuration of a conventional three-phase 12/10-pole FSPM machine, which is more like a doubly salient motor with hybrid excitation by adding PMs in the stator. The stator core is separated into twelve modular pieces of " $U$ shaped" lamination segments. Compared to conventional PMSMs, the PMs and concentrated windings are all installed in the stator, which presents inherently sinusoidal flux-linkage, high speed, and high torque capabilities. However, high cogging torque is introduced in FSPM machines due to the doubly salient structure, leading to vibration and noise. Moreover, the modular stator structure is relatively weak mechanically and also increases the assembly complexity, which tends to introduce much more significant manufacturing tolerance and increase the cogging torque [11].

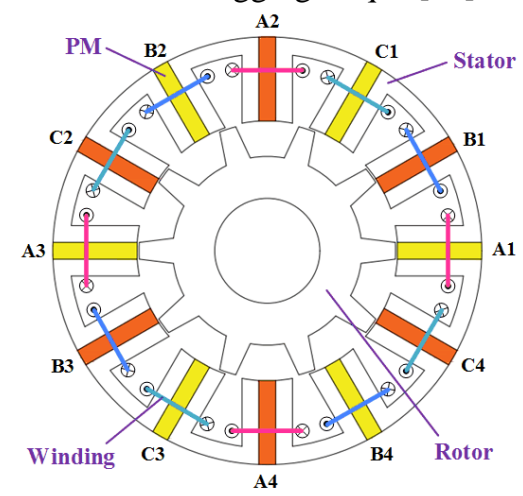

Fig. 1. Cross section of traditional FSPM machine.

The cogging torque in FSPM machines can be expressed as the derivative of the magnetic co-energy:

$$
T_{\operatorname{cog}}=-\frac{\partial W}{\partial \theta}
$$

where $\theta$ is the rotor position angle, and $W$ is the magnetic coenergy.

Considering that the permeability of the iron core is much larger than that of the air-gap and PMs, the magnetic co-energy ignoring the energy variation in the iron core can be replaced by that stored in the air-gap [18], [21]

$$
W \approx W_{\text {gap }}=\frac{1}{2 \mu_{0}} \int_{V} B^{2}(\theta) d V=\frac{1}{2 \mu_{0}} \int_{V} B_{r}^{2}(\theta) G^{2}(\theta, \alpha) d V
$$

where $\mu_{0}$ is the permeability of the air, $\theta$ is the angle along the circumference of air-gap, $B(\theta)$ is the flux density distribution in the air-gap along the circumference, $B_{r}(\theta)$ is the flux density distribution generated by PMs in the stator, and $G(\theta, \alpha)$ is the influence of salient rotor on stator flux density.

The number of the cogging torque periods during a rotation of a slot pitch depends on the number of slots and poles, which is given by [29]

$$
N_{p}=\frac{N_{r}}{H C F\left(N_{s}, N_{r}\right)}
$$

where $N_{\mathrm{s}}$ and $N_{\mathrm{r}}$ are the numbers of stator slots and motor poles, respectively, and the denominator is the highest common factor (HCF) between $N_{\mathrm{s}}$ and $N_{\mathrm{r}}$. In a 12/10-pole machine, $N_{\mathrm{s}}$ is 12 and $N_{\mathrm{r}}$ is 10 , and thus the number of the cogging torque periods during a rotation of a slot pitch is 5 .

Therefore, the mechanical angle for each period should be

$$
\beta_{\operatorname{cog}}=\frac{360^{\circ}}{N_{p} \cdot N_{s}}=\frac{360^{\circ}}{5 \times 12}=6^{\circ}
$$

\section{B. FSPM Machine with Stator FB}

The stator core is segmented and modularized, which is difficult to assemble. In order to reduce the manufacturing complexity and make the stator more robust, the stator FB can be added in the stator to connect each stator segment, which 
makes the stator as a single unit. Adding the stator FB in adjacent stator tooth not only reduces the manufacturing complexity and achieves a more robust stator configuration, but also alleviates the cogging torque [24]. However, different FB placing positions are not investigated in details. As illustrated in Fig. 2, there are two positions to add the stator FB, including the inner side (where the FB is placed at the adjacent stator pole) and the outer side (where the FB is placed at the adjacent stator yoke). In addition, the thickness of the FB is another important factor related to the performance. In order to investigate the FB placing position and thickness, a two-dimensional (2D) finite element simulation is conducted in Ansoft FEM environment. The main parameters of the original machine prototype are shown in Table I. The dimensions and ratings of the investigated SFPM machines are the same for the comparative study, and the only differences between these configurations are their FB thickness and placing position. The FB thickness is set to $0 \mathrm{~mm}, 0.5 \mathrm{~mm}, 1.5 \mathrm{~mm}$, and $2 \mathrm{~mm}$ for comparison.

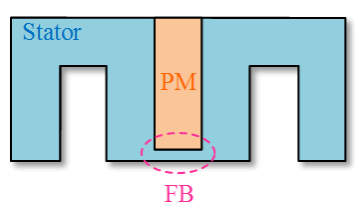

(a) Inner side

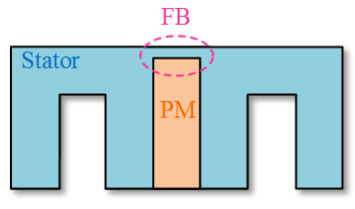

(b) Outer side
Fig. 2. Position of the stator FB.

TABLE I

FSPM MACHINE PARAMETERS

\begin{tabular}{ccc}
\hline \hline Parameter & Unit & Value \\
\hline Phase number & - & 3 \\
Stator/rotor poles & - & $12 / 10$ \\
Rated power & $\mathrm{W}$ & 750 \\
Rated speed & $\mathrm{r} / \mathrm{min}$ & 1500 \\
Stator outer diameter & $\mathrm{mm}$ & 102 \\
Stator inner diameter & $\mathrm{mm}$ & 62 \\
Stator pole arc angle & $\mathrm{deg}$ & 22 \\
Stator yoke length & $\mathrm{mm}$ & 4 \\
Stator tooth width & $\mathrm{mm}$ & 12 \\
PM width & $\mathrm{mm}$ & 4 \\
PM length & $\mathrm{mm}$ & 20 \\
Rotor outer diameter & $\mathrm{mm}$ & 61 \\
Rotor inner diameter & $\mathrm{mm}$ & 25 \\
Rotor pole arc angle & $\mathrm{deg}$ & 8 \\
Rotor tooth width & $\mathrm{mm}$ & 4 \\
Core length & $\mathrm{mm}$ & 60 \\
Number of turns & - & 41 \\
Air gap length & $\mathrm{mm}$ & 0.5 \\
\hline \hline
\end{tabular}

Fig. 3 shows the back electromotive force (EMF) under different FB positions and thickness. The back EMF is a sine waveform and the amplitude is largest, when there is no FB in the stator. When the FB is added at the inner side, the back EMF decreases along with the FB thickness increasing and changes to a trapezoidal waveform, as shown in Fig. 3(a). However, the back EMF decreases slightly when the FB thickness increases, if the FB is added at the outer side, and the back EMF keeps a sine waveform, as shown in Fig. 3(b).

The cogging torque and average output torque under different FB positions and thickness are compared in Fig. 4. From the cogging torque comparison in Fig. 4(a), it can be found that, at the same FB placing position, the cogging torque reduces along with the increasing of the bridge thickness; at the same FB thickness, the cogging torque of the inner structure is less than that of the outer structure; the cogging torque is minimum when the FB is added at the inner side with $2 \mathrm{~mm}$ thickness. As shown in Fig. 4(b), although adding the FB at the inner side can reduce the cogging torque significantly, it leads to higher output torque loss. However, adding the FB at the outer side can obtain larger output torque than at the inner side and the average output torque decreases slightly when the FB thickness increases until $1 \mathrm{~mm}$.

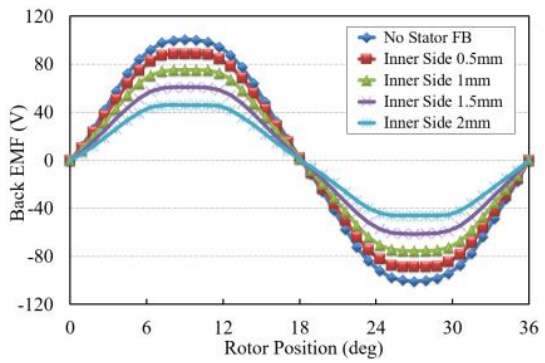

(a)

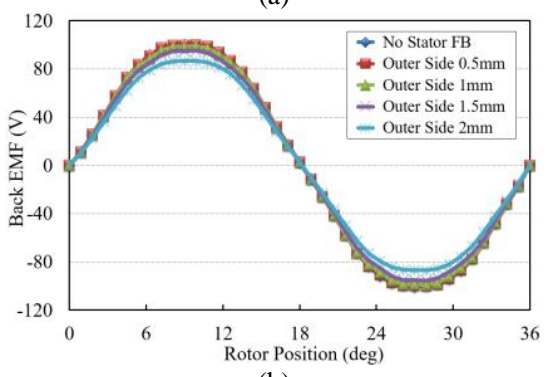

(b)

Fig. 3. Back EMF under different FB positions and thickness. (a) Inner side. (b) Outer side.

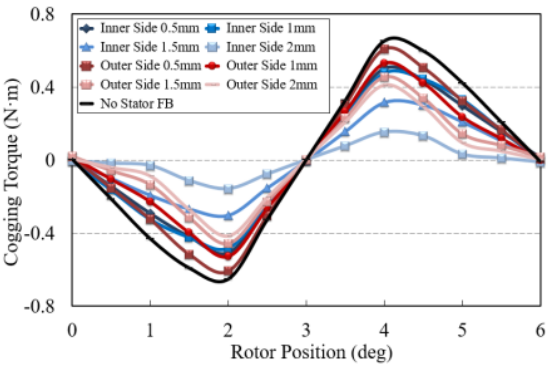

(a)

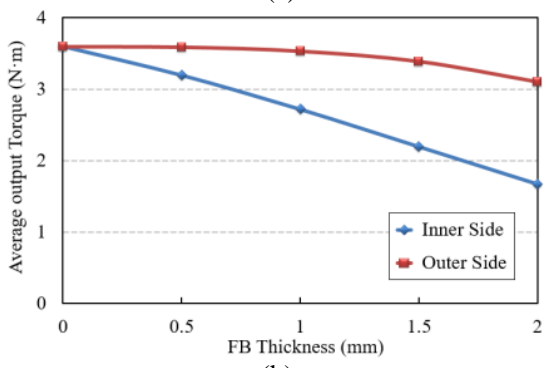

(b)

Fig. 4. Cogging torque and average output torque at different rotor positions. (a) Cogging torque. (b) Average output torque.

\section{FEM SIMULATION FOR DEVELOPED FSPM MACHINES}

In order to investigate the PM length effect on the cogging torque reduction in FSPM machines with stator FB, this paper presents four developed machine topologies, including innerinner topology, inner-outer topology, outer-inner topology, and outer-outer topology, by reducing the PM length towards inner or outer directions at different stator FB placing positions, as 
shown in Fig. 5. Five magnet lengths, including $15 \mathrm{~mm}, 16 \mathrm{~mm}$, $17 \mathrm{~mm}, 18 \mathrm{~mm}$, and $19 \mathrm{~mm}$ are selected for comparison, and the stator lamination bridge thickness is set to $1 \mathrm{~mm}$. The 2D FEM simulation models for the developed three-phase 12/10pole FSPM machines are established for the investigation. The design specifications for the FSPM machines are shown in Table I. The dimensions and ratings of the four topologies are the same for the comparative study, and the only differences are the PM length and FB placing position. The machines are simulated in the same operations under 3 Arms phase current and $1500 \mathrm{r} / \mathrm{min}$ rated speed.

In order to observe the variation of the cogging torque and average output torque with reduced PM length compared to the condition at $19 \mathrm{~mm}$ regular PM length, normalized values are employed as follows:

$$
\begin{gathered}
T_{c o g}{ }^{*}=T_{c o g} / T_{\operatorname{cog}_{-} 19} \\
T_{a v}{ }^{*}=T_{a v} / T_{a v_{-} 19}
\end{gathered}
$$

where $T_{\operatorname{cog}}{ }^{*}$ and $T_{\mathrm{av}}{ }^{*}$ are the normalized peak cogging torque and average output torque, respectively; $T_{\operatorname{cog}}$ and $T_{\mathrm{av}}$ are the actual peak cogging torque and average output torque, respectively; $T_{\text {cog_19 }}$ and $T_{\text {av_19 }}$ are the peak cogging torque and average output torque at $19 \mathrm{~mm}$ PM length, respectively.

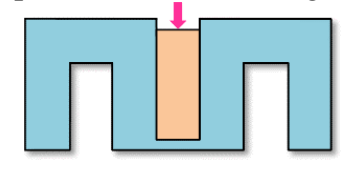

(a)

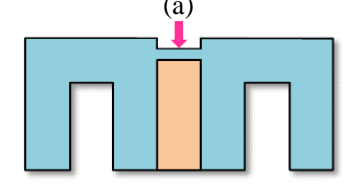

(c)

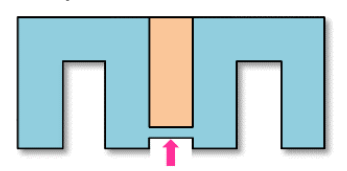

(b)

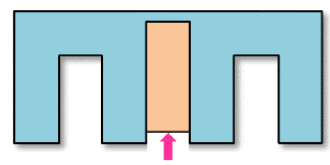

(d)
Fig. 5. Four FSPM machine topologies with short PM and stator FB. (a) Innerinner topology. (b) Inner-outer topology. (c) Outer-inner topology. (d) Outerouter topology.

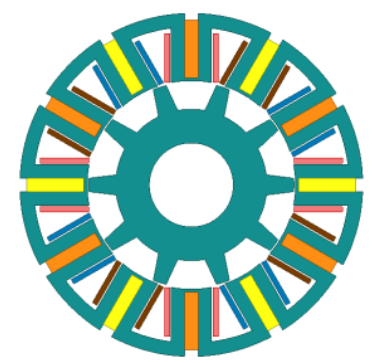

(a)

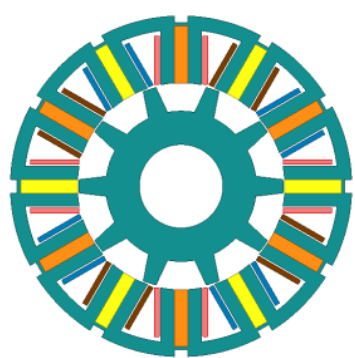

(c)

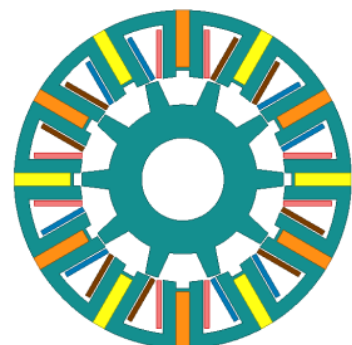

(b)

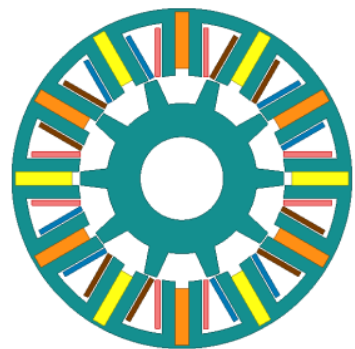

(d)
Fig. 6. Finite element simulation models for developed three-phase 12/10-pole FSPM machines. (a) Inner-inner topology. (b) Inner-outer topology. (c) Outerinner topology. (d) Outer-outer topology.

\section{A. Inner-Inner Topology}

In this topology, the stator FB is added at the inner side and the PM length is reduced towards the inner axial direction, as shown in Fig. 5(a) and Fig. 6(a). Fig. 7 presents the simulation results of the cogging torque and average output torque for the inner-inner topology under different PM lengths. The cogging torque decreases slightly when the PM length is reduced from 19 to $15 \mathrm{~mm}$, as shown in Fig. 7(a). Fig. 7(b) illustrates the relationship between the normalized average output torque and the normalized peak value of the cogging torque, along with the PM length variation. The average output torque does not change obviously when the PM length is reduced, and the cogging torque at $15 \mathrm{~mm}$ PM length is only reduced by $17 \%$ compared to that at $19 \mathrm{~mm}$ PM length, as shown in Fig. 7(b).

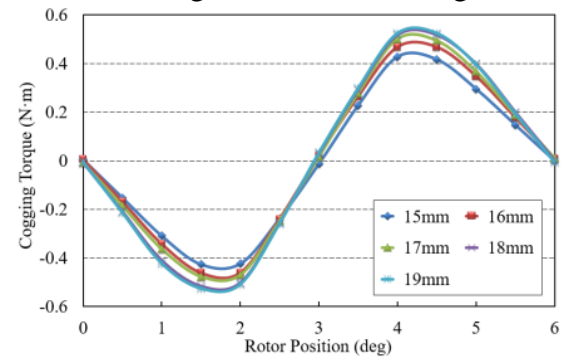

(a)

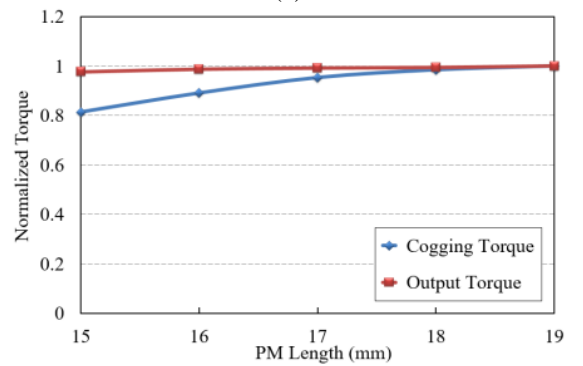

(b)

Fig. 7. Cogging torque and average output torque for inner-inner topology at different PM lengths. (a) Cogging torque. (b) Normalized average output torque and cogging torque.

\section{B. Inner-Outer Topology}

The inner-outer topology is shown in Fig. 5(b) and Fig. 6(b), where the stator FB is added at the inner side and the PM length is reduced towards the outer direction. The simulation results of the cogging torque and average output torque for the inner-outer topology under different PM lengths are presented in Fig. 8. Compared to the inner-inner topology, the cogging torque reduces significantly with the PM length decreasing, as shown in Fig. 8(a). When the PM length is reduced to $17 \mathrm{~mm}$, the peak value of the cogging torque reduces to $40 \%$ of $19 \mathrm{~mm}$ structure. However, the cogging torque only decreases a little, if the PM length is continually reduced from 17 to $15 \mathrm{~mm}$. In Fig. 8(b), the normalized average output torque decreases significantly along with the PM length reduction. Therefore, the $17 \mathrm{~mm} \mathrm{PM}$ length is a critical point, where the cogging torque can be reduced with less output torque loss. The cogging torque at 17 $\mathrm{mm}$ PM length is reduced by $60 \%$ compared to $19 \mathrm{~mm} \mathrm{PM}$ length, at $20 \%$ cost of average output torque. 


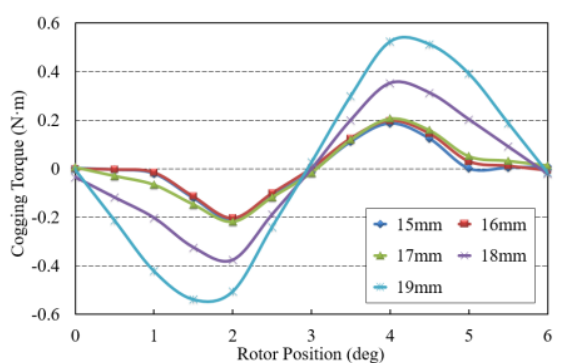

(a)

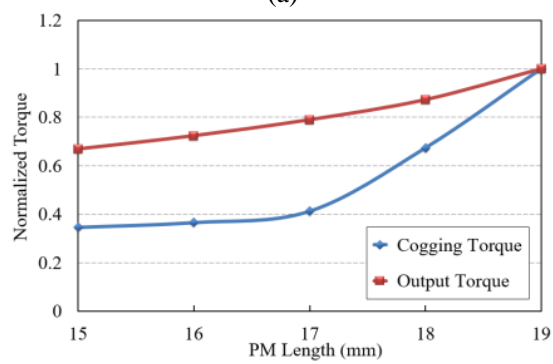

(b)

Fig. 8. Cogging torque and average output torque for inner-outer topology at different PM lengths. (a) Cogging torque. (b) Normalized average output torque and cogging torque.

\section{Outer-Inner Topology}

Fig. 5(c) and Fig. 6(c) illustrated the outer-inner topology, where the stator FB is added at the outer side and the PM length is reduced towards the inner direction. Fig. 9(a) shows the relationship between the cogging torque and PM length in the outer-inner topology. Clearly, the cogging torque reduces obviously along with the decreasing of the PM length, where the cogging torque is minimum at $15 \mathrm{~mm}$ PM length. The normalized cogging torque and average output torque are both shown in Fig. 9(b). It can be seen that the average output torque decreases continuously when the PM length reduces from 19 to $15 \mathrm{~mm}$, while the decreasing is much smaller than that in innerouter topology. Although the cogging torque can be reduced greatly at $15 \mathrm{~mm}$ PM length, the average output torque loss is large. Similar to the inner-outer topology, $17 \mathrm{~mm}$ PM length is more effective to reduce the cogging torque at only slight cost of average output torque. Compared to the $19 \mathrm{~mm}$ topology, the peak value of the cogging torque is reduced by $28.5 \%$ at only $6.5 \%$ torque loss.

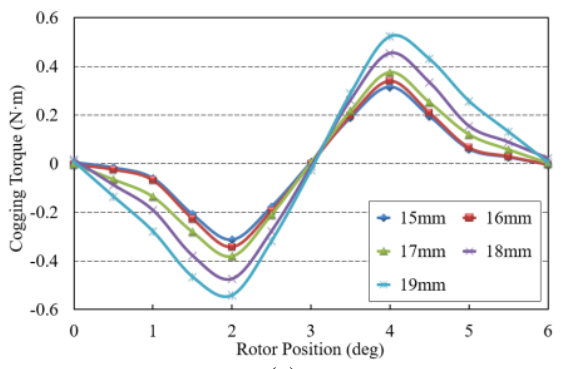

(a)

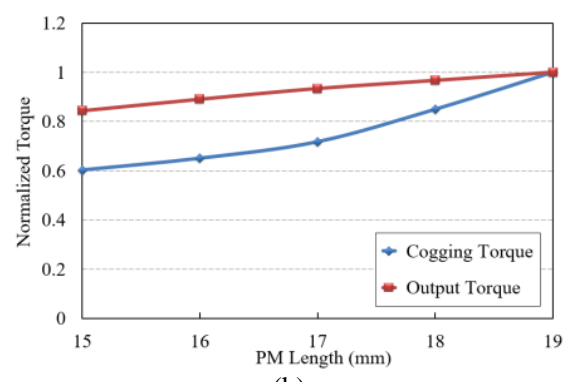

(b)

Fig. 9. Cogging torque and average output torque for inner-inner topology at different PM lengths. (a) Cogging torque. (b) Normalized average output torque and cogging torque.

\section{Outer-Outer Topology}

In the outer-outer topology, the stator FB is added at the outer side and the PM length is reduced towards the outer direction, as shown in Fig. 5(d) and Fig. 6(d). The variation tendency of the cogging torque and average output torque in this topology is similar to the outer-inner topology, as shown in Fig. 10. The cogging torque declines along with the reducing of the PM length. However, the average output torque decreases more compared to the outer-inner topology. Similarly, in $17 \mathrm{~mm}$ PM length topology, the peak value of the cogging torque is reduced by $32 \%$ and the torque loss is $13 \%$, compared to the $19 \mathrm{~mm}$ PM length topology.

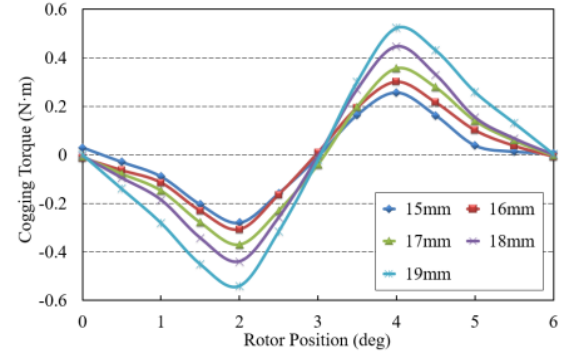

(a)

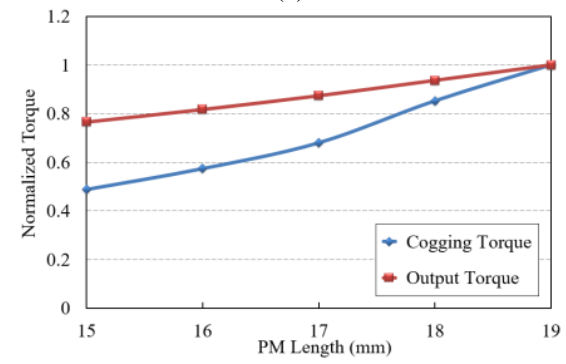

(b)

Fig. 10. Cogging torque and average output torque for outer-outer topology at different PM lengths. (a) Cogging torque. (b) Normalized average output torque and cogging torque.

\section{E. Comparison of Developed FSPM Machine Topologies}

A comparison of the four developed FSPM machine topologies at different PM lengths is illustrated in Fig. 11, including the cogging torque, average output torque, PM utilization ratio, and torque ripple. In order to achieve a more effective comparison for the cogging torque and average output torque in each topology, they are all normalized according to the values in the outer-inner topology.

As shown in Fig. 11(a), the peak cogging torques of the four topologies are almost the same when the PM length is $19 \mathrm{~mm}$. The cogging torque can be reduced in all the topologies by shortening the PM length, while the effect is most obvious in 
the inner-outer topology and slightest in inner-inner topology. In Fig. 11(b), it can be seen that reducing the PM length leads to torque loss in all the machines; the output torques are the same in outer-inner and outer-outer topologies at $19 \mathrm{~mm}$ PM length; the output torques are the same in inner-inner and innerouter topologies at $19 \mathrm{~mm}$ PM length, which are only $77 \%$ of the values in outer-inner and outer-outer topologies. Therefore, in order to reduce the cogging torque with less torque loss, placing the stator FB at the outer side is a more efficient solution. However, to ensure the average output torque, the PM length should not be shorter than $17 \mathrm{~mm}$.

Fig. 11(c) presents the PM utilization ratio related to the output torque, where the PM utilization is highest in the outerinner topology. Fig. 11(d) shows the comparison of the torque ripple. Clearly, the torque ripple decreases slightly when the $\mathrm{PM}$ length is reduced in the inner-inner topology; when the PM length is reduced to $17 \mathrm{~mm}$, the torque ripple can be significantly reduced in inner-inner, outer-inner, and outerouter topologies; the torque ripple is not changed obviously if the PM length is continually reduced from 17 to $15 \mathrm{~mm}$ in these three topologies.

From the analysis above, considering the back EMF, cogging torque, average output torque, and also manufacturing complexity, the outer-inner topology with $17 \mathrm{~mm}$ PM length is a better solution to mitigate the cogging torque with higher output torque. The cogging torque can be reduced by $28.5 \%$ at only $6.5 \%$ torque loss, compared to $19 \mathrm{~mm}$ PM length topology. The PM is reduced by $11 \%$, which also increases the PM utilization ratio and reduces the cost. Therefore, the outer-inner topologies with $17 \mathrm{~mm}$ PM length and $19 \mathrm{~mm}$ regular PM length are employed for further experimental verification and comparison.

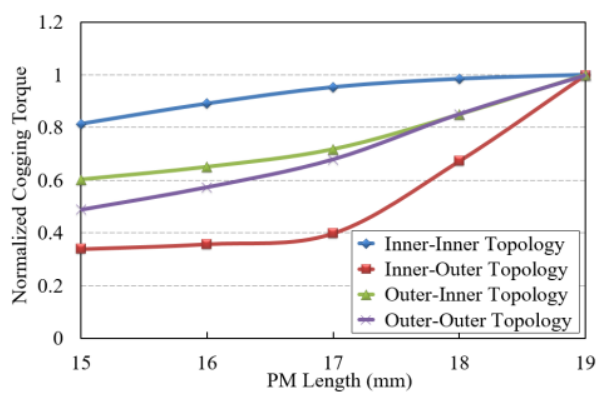

(a)

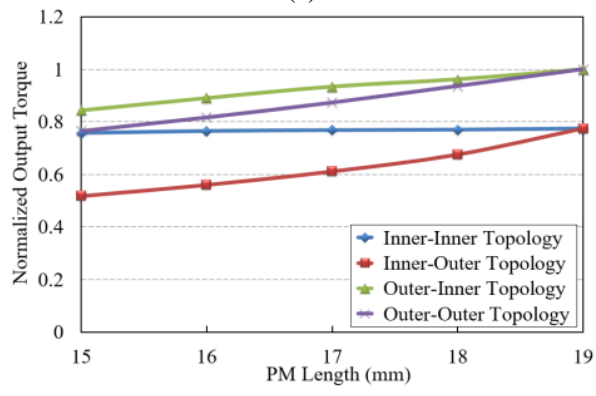

(b)

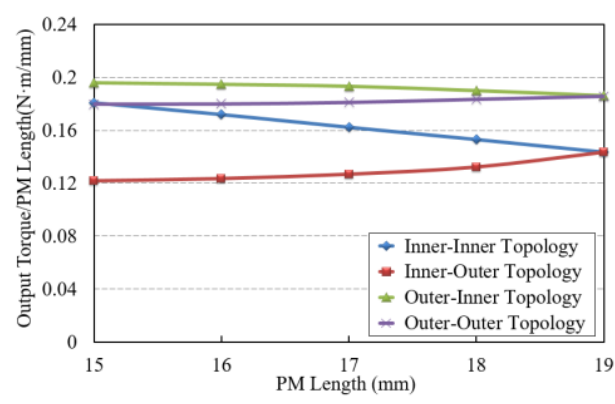

(c)

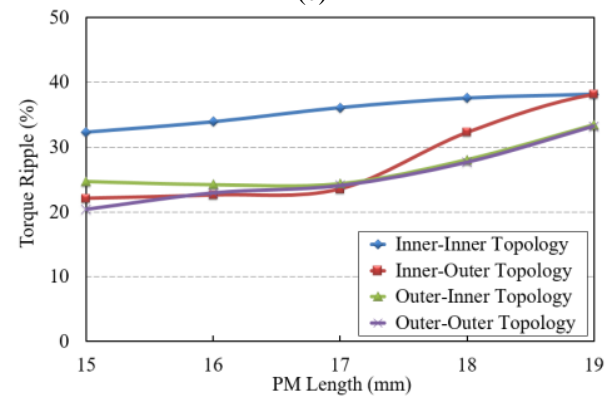

(d)

Fig. 11. Comparison of FSPM Machine Topologies. (a) Cogging torque. (b) Average output torque. (c) PM utilization ratio. (d) Torque ripple.

\section{EXPERIMENTAL RESULTS}

In order to investigate the performance of the developed FSPM topologies in experiments, two machines are designed and prototyped for experimental validation, including the outerinner FSPM machine with $19 \mathrm{~mm}$ regular PM length and $1 \mathrm{~mm}$ stator FB, and the outer-inner topology with $17 \mathrm{~mm}$ short PM length and $1 \mathrm{~mm}$ stator FB. The dimensions and ratings of the machines have been shown in Table I. The prototypes of the manufactural FSPM machines are shown in Fig. 12(a) and (b). An experimental setup is developed for tests, as shown in Fig. 12 (c). In the motor test bed, a Parker AC servomotor acts as the load, which is controlled by an integrated load controller inside the cabinet. A high-precision torque sensor is installed between the FSPM prototype and load motor to detect the instantaneous output torque. A three degree of freedom (3-DOF) bracket is designed to achieve the balanced connection. The cogging torque is measured from the torque sensor by using a high-precision index head to fix the rotor position.

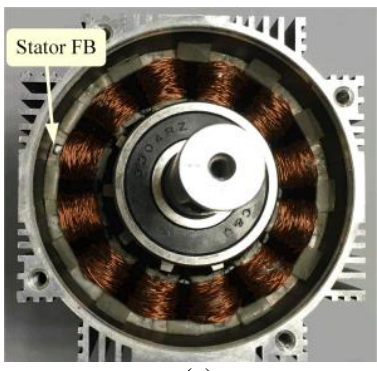

(a)

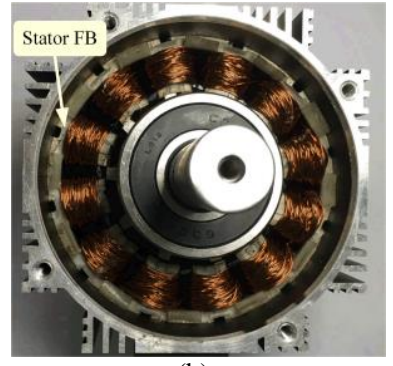

(b) 


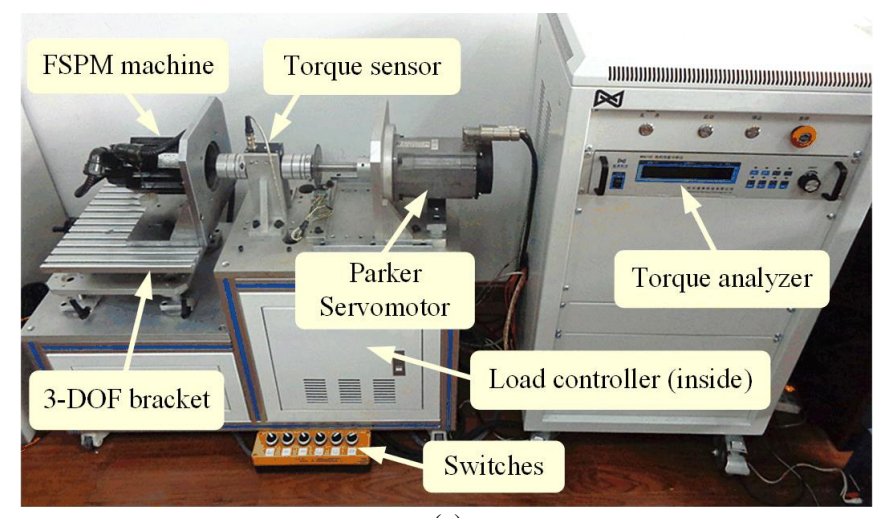

(c)

Fig. 12. Photographs of the FSPM machines and experimental test-rig. (a) Outer-inner topology with regular PM length and FB. (b) Outer-inner topology with short PM length and FB. (c) Experimental test-rig.

Fig. 13 presents the experimental results of the cogging torque in regular PM length and short PM length topologies. Simulation results are also added in the figures to show the comparisons. For the regular PM length topology, the peak cogging torque is $0.52 \mathrm{~N} \cdot \mathrm{m}$ in the simulation and $0.55 \mathrm{~N} \cdot \mathrm{m}$ in the experiment. For the short PM length topology, the peak cogging torques are $0.37 \mathrm{~N} \cdot \mathrm{m}$ and $0.38 \mathrm{~N} \cdot \mathrm{m}$ in the simulation and experiment, respectively. Clearly, the experimental results match well with the simulation results in both topologies. Due to the short PM effect, the cogging torque is reduced by $31 \%$ compared to the regular one, which matches well with the simulation result.

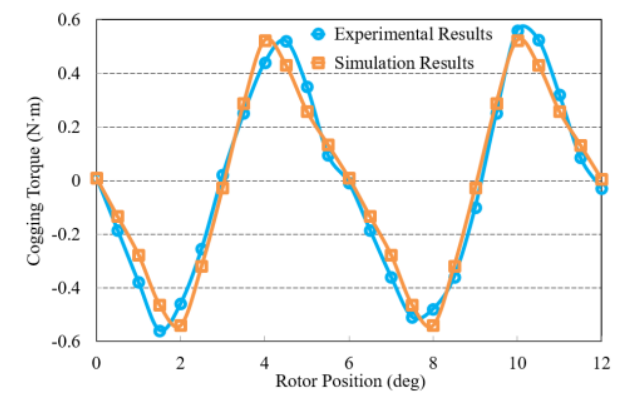

(a)

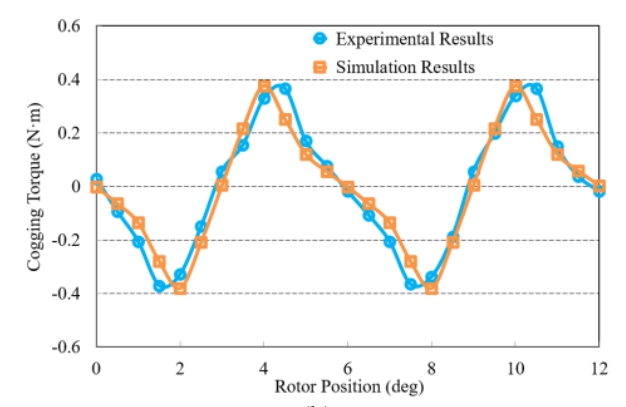

(b)

Fig. 13. Cogging torque results. (a) Regular PM length. (b) Short PM length.

Fig. 14 shows the measured no-load phase back EMF waveforms at $1500 \mathrm{r} / \mathrm{min}$ with regular and short PM length, where $U_{e a}, U_{e b}$, and $U_{e c}$ are the back EMF voltages of phase A, $\mathrm{B}$ and $\mathrm{C}$, respectively. The corresponding back-EMF waveforms at rated speed in both machine topologies appear to be sinusoidal and symmetric. The back EMF of the short PM length topology only has a slight reduction from that of the regular PM length topology, leading to a slight reduction in output torque, which shows the usual performance tradeoff associated with cogging torque reduction methods [17].

The experimental waveforms of the phase current and output torque at low and rated speeds are illustrated in Fig. 15, where the phase current is set to 3 Arms, which is the same to the simulation. In the figure, $i_{a}$ and $T_{\text {out }}$ are the phase A current and output torque, respectively. When the machines operate at 300 $\mathrm{r} / \mathrm{min}$, the average output torque of the regular PM length topology is $3.35 \mathrm{~N} \cdot \mathrm{m}$, while $3.16 \mathrm{~N} \cdot \mathrm{m}$ in the short PM length topology, where the torque loss is about $5.6 \%$. At $1500 \mathrm{r} / \mathrm{min}$, the average output torques of the regular PM length and short PM length topologies are $3.25 \mathrm{~N} \cdot \mathrm{m}$ and $3.03 \mathrm{~N} \cdot \mathrm{m}$, respectively, where the torque loss is about $6.7 \%$, which is similar to the simulation results. Therefore, the cogging torque can be significantly reduced at only slight cost of average output torque by shortening the PM to an appropriate length.

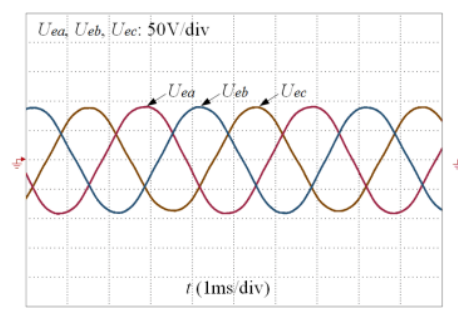

(a)

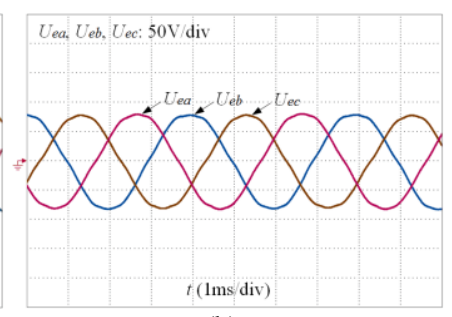

(b)
Fig. 14. Back EMF waveforms. (a) Regular PM length. (b) Short PM length.

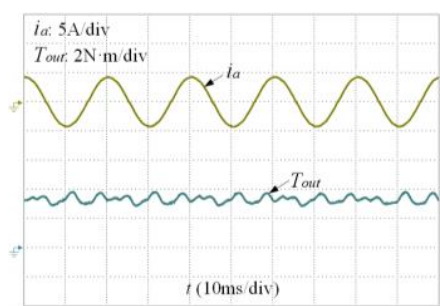

(a)

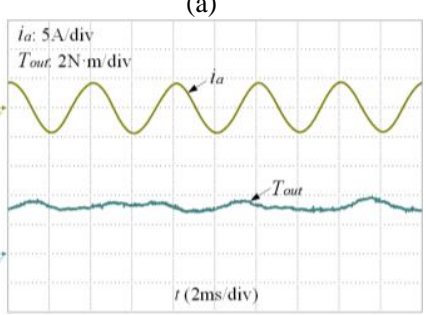

(c)

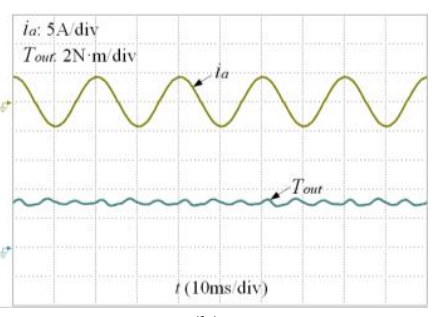

(b)

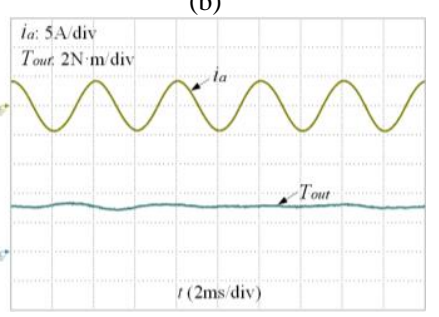

(d)
Fig. 15. Current and output torque waveforms. (a) Regular PM length topology at $300 \mathrm{r} / \mathrm{min}$. (b) Short PM length topology at $300 \mathrm{r} / \mathrm{min}$. (c) Regular PM length topology at $1500 \mathrm{r} / \mathrm{min}$. (d) Short PM length topology at $1500 \mathrm{r} / \mathrm{min}$.

In order to investigate the performance of the developed FSPM machines at different speeds, Fig. 16 presents the efficiency and output torque comparisons between the regular PM and short PM topologies. It is clear that the efficiency is not obviously degraded in the developed machine system (only $1.5 \%$ ), although the PM length is reduced by $11 \%$, as shown in Fig. 16(a). The output torque is decreased by 5.6\% $6.7 \%$ from 300 to $1500 \mathrm{r} / \mathrm{min}$, as shown in Fig. 16(b), confirming that the developed machine topology will effectively reduce the cogging torque at only slight cost of machine performance. 


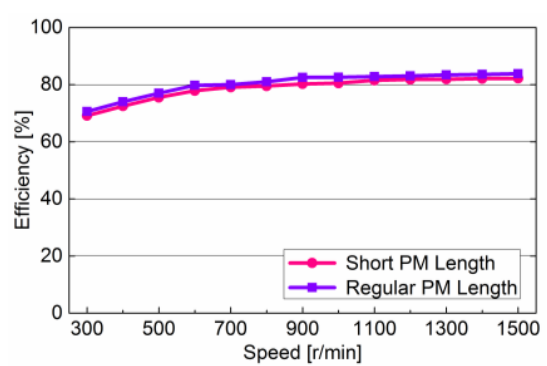

(a)

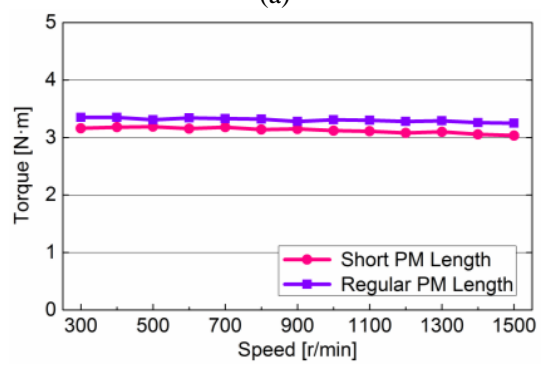

(b)

Fig. 16. Comparison of efficiency and torque ripple for different topologies. (a) Efficiency. (b) Average output torque. (y axis zoom in)

\section{CONCLUSION}

In this paper, four different three-phase 12/10-pole FSPM machines, including the inner-inner topology, inner-outer topology, outer-inner topology, and outer-outer topology are introduced to investigate the effects of short PMs and stator FBs on the cogging torque reduction, which is the main source of vibration and noise of FSPMs. The machines with different FB positions and thickness are firstly analyzed and compared. Then, the cogging torque and average output torque under different PM length for the four developed machines with stator FB are compared in details, by establishing FEM models in Ansoft environment. Two selected machines are designed and prototyped for further experimental validation, including the outer-inner FSPM machine with regular PM length and the outer-inner topology with short PMs.

From this work, the following are found.

1) The stator FB achieves a more robust stator configuration and alleviates the cogging torque. Adding the stator FB at outer side can obtain larger output torque than at inner side.

2) Reducing the PM length can decrease the cogging torque effectively in all four topologies, while the torque loss is largest in the inner-outer topology and smallest in the outer-inner topology.

3) The outer-inner topology with $17 \mathrm{~mm}$ PM length is a better solution to mitigate the cogging torque. Compared to the machine with regular PM length, the cogging torque can be reduced by $31 \%$ at only $6.7 \%$ output torque loss and $1.5 \%$ efficiency loss. The PM is reduced by $11 \%$, which also increases the PM utilization ratio and reduces the cost.

4) It is suggested that adding the stator FB on the outer side and reducing the PM length on the inner side is more effective to mitigate the cogging torque due to less performance loss.

Although the work has targeted electrified vehicle applications, the developed technologies can be applied to other high-torque, high-speed applications such as more-electric aircraft, traction drives and electrical ships.

\section{ACKNOWLEDGMENT}

This work was supported in part by the Chinese National 863 program under Project 2011AA11A101, and the National Nature Science Foundation of China under Project 51377139.

\section{REFERENCES}

[1] L. Shao, W. Hua, Z. Q. Zhu, X. Zhu, M. Cheng and Z. Wu, "A novel fluxswitching permanent magnet machine with overlapping windings," IEEE Trans. Energy Convers., vol. 32, no. 1, pp. 172-183, Mar. 2017.

[2] T. Wang, C. Liu, W. Xu, G. Lei, M. Jafari, Y. Guo, J. Zhu, "Fabrication and experimental analysis of an axially laminated flux-switching permanent-magnet machine," IEEE Trans. Ind. Electron., vol. 64, no. 2, pp. 1081-1091, Feb. 2017.

[3] W. Hua, H. Zhang, M. Cheng, J. Meng and C. Hou, "An outer-rotor fluxswitching permanent-magnet-machine with wedge-shaped magnets for in-wheel light traction," IEEE Trans. Ind. Electron., vol. 64, no. 1, pp. 6980, Jan. 2017.

[4] X. Zhu, Z. Shu, L. Quan, Z. Xiang and X. Pan, "Multi-objective optimization of an outer-Rotor $\mathrm{V}$-shaped permanent magnet flux switching motor based on multi-level design method," IEEE Trans. Magn., vol. 52, no. 10, Oct. 2016, Art. no. 8205508.

[5] D. Kim, H. Hwang, S. Bae and C. Lee, "Analysis and design of a doublestator flux-switching permanent magnet machine using ferrite magnet in hybrid electric vehicles," IEEE Trans. Magn., vol. 52, no. 7, pp. 1-4, Jul. 2016, Art. no. 8106604.

[6] M. Cheng, F. Yu, K. T. Chau and W. Hua, "Dynamic performance evaluation of a nine-phase flux-switching permanent-magnet motor drive with model predictive control," IEEE Trans. Ind. Electron., vol. 63, no. 7, pp. 4539-4549, Jul. 2016.

[7] D. Li, R. Qu, J. Li, W. Xu and L. Wu, "Synthesis of Flux Switching Permanent Magnet Machines," IEEE Trans. Energy Convers., vol. 31, no. 1, pp. 106-117, Mar. 2016.

[8] W. Hua, G. Zhang and M. Cheng, "Investigation and design of a highpower flux-switching permanent magnet machine for hybrid electric vehicles," IEEE Trans. Magn., vol. 51, no. 3, pp. 1-5, Mar. 2015.

[9] D. Xu, M. Lin, X. Fu, L. Hao, W. Zhang and N. Li, "Cogging torque reduction of a hybrid axial field flux-switching permanent-magnet machine with three methods," IEEE Trans. Appl. Supercond., vol. 26, no. 4, Jun. 2016, Art. no. 5201305.

[10] L. Hao, M. Lin, D. Xu, N. Li and W. Zhang, "Analysis of cogging torque reduction techniques in axial-field flux-switching permanent-magnet machine," IEEE Trans. Appl. Supercond., vol. 26, no. 4, Jun. 2016, Art. no. 5200605 .

[11] Z. Q. Zhu, A. S. Thomas, J. T. Chen, and G. W. Jewell, "Cogging torque in flux-switching permanent magnet machines," IEEE Trans. Magn., vol. 45, no. 10, pp. 4708-4711, Oct. 2009.

[12] H. Y. Jia, M. Cheng, W. Hua, Z. Z. Yang, and Y. Q. Zhang, "Compensation of cogging torque for flux-switching permanent magnet motor based on current harmonics injection," IEEE International Electric Machines and Drives Conference, pp. 286-291, 2009.

[13] Y. J. Gu, L. Quan, and Z. X. Xiang, "Minimization the torque ripple of flux-switching permanent magnet motor based on iterative learning control," International Conference on Electrical Machines and Systems, pp. 1985-1989, 2014.

[14] W. Huang, and W. Hua, "A finite-control-set-based model-predictiveflux-control strategy with iterative learning control for torque ripple minimization of flux-switching permanent magnet machines," IEEE Vehicle Power and Propulsion Conference (VPPC), pp. 1-6, 2016.

[15] T. H. Kim, S. H. Won, K. Bong, and J. Lee, "Reduction of cogging torque in flux-reversal machine by rotor teeth pairing," IEEE Trans. Magn., vol. 41, no. 10, pp. 3964-3966, Oct. 2005.

[16] Y. Wang, M. J. Jin, W. Z. Fei, and J. X. Shen, "Cogging torque reduction in permanent magnet flux-switching machines by rotor teeth axial pairing," IET Elect. Power Appl., vol. 4, no. 7, pp. 500-506, Jul. 2010.

[17] W. Fei, P. C. K. Luk, J. X. Shen, B. Xia, and Y. Wang, "Permanentmagnet flux-switching integrated starter generator with different rotor configurations for cogging torque and torque ripple mitigations," IEEE Trans. Ind. Appl., vol. 47, no. 3, pp. 1247-1256, May/Jun. 2011.

[18] D. Wang, X. Wang, and S. Y. Jung, "Reduction on cogging torque in fluxswitching permanent magnet machine by teeth notching schemes," IEEE Trans. Magn., vol. 48, no. 11, pp. 4228-4231, Nov. 2012. 
[19] L. Hao, M. Lin, D. Xu, N. Li, and W. Zhang, "Cogging torque reduction of axial-field flux-switching permanent magnet machine by rotor tooth notching," IEEE Trans. Magn., vol. 51, no. 11, Nov. 2015, Art. no. 8208304.

[20] Y. Wang, and Z. Deng, "A multi-tooth fault-tolerant flux-switching permanent-magnet machine with twisted-rotor," IEEE Trans. Magn., vol. 48, no. 10, pp. 2674-2684, Oct. 2012.

[21] C. Sikder, I. Husain, and W. Ouyang, "Cogging Torque Reduction in Flux-Switching Permanent-Magnet Machines by Rotor Pole Shaping," IEEE Trans. Ind. Appl., vol. 51, no. 5, pp. 3609-3619, Sep./Oct. 2015.

[22] W. Zhao, T. A. Lipo, and B. I. Kwon, "A novel dual-rotor, axial field, fault-tolerant flux-switching permanent magnet machine with high-torque performance," IEEE Trans. Magn., vol. 51, no. 11, Nov. 2015, Art. no. 8112204.

[23] Y. Li, D. Bobba, and B. Sarlioglu, "A novel 6/4 flux-switching permanent magnet machine designed for high-speed operations," IEEE Trans. Magn., vol. 52, no. 8, Aug. 2016, Art. no. 8107109.

[24] L. Hao, M. Lin, D. Xu, and W. Zhang, "Cogging torque reduction of axial field flux-switching permanent magnet machine by adding magnetic bridge in stator tooth," IEEE Trans. Appl. Supercond., vol. 24, no. 3, pp. 1-5, Jun. 2014, Art. no. 0503405.

[25] G. Wu, and W. Hua, "The influence of permanent magnet length on electromagnetic performance in flux switching machine," International Conference on Electrical Machines and Systems (ICEMS), pp. 218-222, 2015.

[26] W. Hua, G. Zhang, and M. Cheng, "Flux-regulation theories and principles of hybrid-excited flux-switching machines," IEEE Trans. Ind. Electron., vol. 62, no. 9, pp. 5359-5369, Sep. 2015.

[27] X. Xue, W. Zhao, J. Zhu, G. Liu, X. Zhu, and M. Cheng, "Design of fivephase modular flux-switching permanent-magnet machines for high reliability applications," IEEE Trans. Magn., vol. 49, no. 7, pp. 39413944, Jul. 2013.

[28] F. Li, W. Hua, M. Tong, G. Zhao, and M. Cheng, "Nine-phase fluxswitching permanent magnet brushless machine for low-speed and hightorque applications," IEEE Trans. Magn., vol. 51, no. 3, pp. 1-4, Mar. 2015.

[29] N. Bianchi, S. Bolognani, "Design techniques for reducing the cogging torque in surface-mounted PM motors," IEEE Trans. Ind. Appl., vol. 38 no. 5, pp. 1259-1265, Sep./Oct. 2002. 